\title{
Convergênciais e dissonâncias entre Luhmann e Bourdieu: os limites operacionais dos conceitos anomia e autopoiesis
}

\author{
Convergences and dissonances between Luhmann and Bourdieu: the \\ operational limits of anomie and autopoiesis
}

http://dx.doi.org/10.5007/2178-4582.2017v51n1p034

Stephan Treuke

Universidade Federal da Bahia, Salvador/BA, Brasil

\begin{abstract}
Este artigo identifica as principais convergências e dissonâncias metodológicas entre a Teoria dos Sistemas (Luhmann) e a Teoria da Prática (Bourdieu), valendo-se para isso de um contrastivo insight em seus conceitos-chave autopoiesis e anomia. Partindo das reflexões sociológicasfilosóficas de Christian Hartard (2010), o artigo examina criticamente o princípio da recursividade circular perpassando a concepção de sociogênese dos dois autores e o dilema da dupla hermenêutica deflagrado no discernimento emancipador do sujeito. Conclui-se que a recursividade inerente aos dois conceitos construtivista-generativista pressupõe a incorporação de elementos exógenos com capacidade transformatória das estruturas historicamente sedimentadas (Luhmann), respectivamente, dos corpos socializados (Bourdieu), através de processos de diferenciação e distinção, que ocorrem, contudo, dentro de estabelecidas restrições. Ambos autores pleiteiam pelo questionamento crítico do status quo interiorizado pelo sujeito, suscetível de restituir a capacidade de desmascarar as necessidades dóxicas da dupla contingência (Luhmann), respectivamente da legitimação hierárquica disfarçada (Bourdieu), ao observador da terceira ordem.
\end{abstract}

Palavras-chave: Teoria dos Sistemas; Teoria da Prática; Anomia; Autopoiesis.
This paper identifies the main methodological convergences and dissonances between the System Theory (Luhmann) and the Theory of Practice (Bourdieu), confronting the two conceptions with a series of criticisms on the basis of Christian Hartard's ideas (2010). These concentrate on the operational shortcomings of the constitutive elements of society's genesis: anomie and autopoiesis and examine their principles of auto-referential circularity and double hermeneutic. The two concepts serve as a driving force in the constructionalist approach to social theory, in accordance with the dynamic modus operandi of differentiation and distinction which integrates exogenous influences capable to transform historically sedimented or socialized structures. Nonetheless, these processes occur according to established systemic restrictions. Both authors emphasize the importance of critical assessment of the status quo interiorized by the subject. The third order observer assumes the function of emancipatory self-reflection by revealing doxic structures of double contingency and historical legitimized hierarchies of social dominance.

Keywords: System Theory; Theory of Practice; Anomie; Autopoiesis.

\section{Introdução}

Dentro do panorama dos estudos que fazem uma análise comparativa entre as obras teóricas de Niklas Luhmann e Pierre Bourdieu destacam-se as contribuições sociológicas-filosóficas de Christian Hartard (2010), assinalando pela congruência conceitual existente entre ambos os autores com respeito à concepção de um historicamente evoluído universo social constituído pela incessante operação auto-generadora de diferenciação e distinção realizada pelo sujeito. 
Partindo da rejeição de teorias perpetuadoras do dicotômico paradigma subjetivismo/objetivismo, ambos aderem à visão do mundo social como terrain vague assimetricamente organizado conforme princípios não-ontológicos a medida que focalizam a interface relacional entre estrutura e agência, em oposição às suposições teleológicas de uma ordem pré-estabelecida.

Destarte, assiste-se a um deslocamento do centro de gravidade da sociologia como ciência de conhecimento, à medida que a indagação sobre as intercausalidades entre operações e estruturas relega o ser humano a uma posição secundária de padens. Diante da incognoscibilidade da historicamente constituída assimetria do mundo social, alcançar o ponto arquimédico revelador da totalidade social só pode restar uma utopia.

Neste sentido, Bourdieu e Luhmann comungam em partir da hipótese que o progresso evolucionário se realiza na operação generativa-construtivista de permanente diferenciação que - relacionada à categoria temporal estabelecida - estrutura o horizonte de sentidos dos sujeitos inseridos dentro de uma engrenagem sociogenética cujo momento inicial permanece terra incógnita para a observação.

Ambos substituem a ordem ontológica pela inquietude de ordens emergentes que, soldando o passado já discernível com o horizonte do futuro parcialmente determinado, converte o princípio da liberdade de escolha do indivíduo em (im)probabilidades relacionais ao remeter pelo paradoxo que a única certeza da existência social reside na imperatividade de escolher - sem poder selecionar todo nem escolher nada.

A princípio, tudo é possível - ou, invertendo a alegoria leibnitziana: em um mundo criado sem criador, este só poderia ter escolhido o mais imperfeito dos imperfeitos mundos possíveis.

Neste sentido, Luhmann parte na sua Teoria dos Sistemas de um estrutural-funcionalismo parsiano modificado a medida que introduz a pressuposição da auto-organização circular de sistemas (System) que operam um equilíbrio homoestático com seu entorno (Umwelt) ao promover transformações adaptativas dinâmicas via seleção (LUHMANN, 1987). Conforme o construtivismo radical do sociólogo alemão, o mundo como suprema unidade referencial da complexidade - resultado temporizado da perpétua diferenciação binária entre "atualidades" e "potencialidades" - se substancia por uma multidimensionalidade de (sub)sistemas auto-referenciais constituídos por elementos e conexões relacionais.

Operativamente fechado em relação ao seu entorno, estes sistemas emergentes produzem, através da seleção entre processos comunicativos de aproveitamento e descarte de possibilidades, sua própria lógica evolutiva (autopoiesis), ao reduzir simultaneamente a complexidade circunstante. 
Nesta linha de pensamento, o autor busca na ideia de complexidade a superação da relação causa-efeito da concepção teleológica ocidental, ideia passível de desconstrução e "desparadoxização" pelo observador da terceira ordem, desprovido, contudo, do acesso irrestrito ao entorno integral (LUHMANN, 1998).

Principalmente, as críticas dirigidas contra a teoria de Luhmann assinalam pelo paradoxo metodológico entre a suposta neutralidade operacional inerente ao mecanismo de diferenciação binária - que considera o sujeito como mera entidade portadora de atos comunicacionais com capacidades emancipatórias significantemente limitadas - e a insistência em mecanismos inalteráveis dentro da lógica intrassistêmica de autopoiesis (BÜHL, 2000; HARTARD, 2010; NEVES; NEVES, 2006).

Conquanto menos radical na sua formulação, princípios similares de recursividade operacional subjazem aos axiomas epistemológicos da Teoria da Prática, concebida por Bourdieu no intuito de superar a secular dicotomia objetivismo/subjetivismo através da introdução da categoria intermediadora de práxis. Esta focaliza a imbricação dialética entre condutas individuais fundamentadas em disposições socialmente adquiridas e encarnadas em um infraconsciente habitus, por um lado, e estruturas objetivas ou "campos" de relações entre sujeitos diferencialmente posicionados e empoderados, por outro lado (PETERS, 2013).

Proporcionando uma virada relacional ao modo de pensamento das ciências sociais, o conceito de habitus remete para o conjunto das propensões práticas de conduta subjetivamente interiorizadas pelos agentes, a partir de suas experiências socialmente ancoradas e recursivamente mobilizadas por eles na geração das práticas pelas quais o mundo social se reproduz ou se transforma. A idealtípica convergência ("cumplicidade ontológica") entre ambas as esferas dicotômicas se produz através da operação tácita ou "pré-reflexiva" de um habitus como intermediador causal entre o individual e o social.

As hiperstasiadas estruturas numênicas dominando o conceito anomia através da consecução ou manutenção de múltiplas formas de capital assim como a categórica omissão de circunstâncias desconsiderando as assimetrias (in)variáveis têm provocado uma série de críticas (HARTARD, 2010; NEVES; NEVES, 2006; PETERS, 2013; VANDENBERGHE, 1999). Estas qualificam sua teoria como proposta neo-objetivista das desigualdades sociais com hipertrofiada prevalência de determinismos historicamente transmissíveis.

Consoante as asserções de Peters (2013), a precedência ontológica e metodológica das estruturas socialmente geradas sobre o nível subjetivo dentro do estruturalismo construtivista bourdieusiana inviabiliza - no 
principal momento evolutivo proporcionado pela ruptura com a "cumplicidade ontológica" entre as disposições dos agentes e seus ambientes estruturais de atuação/experiência através do efeito de hysteresis ou de auto-objetivação em forma de "anamnese" pela própria sociologia - a transformação emancipatória das estruturas a partir da refletividade do sujeito.

Seguindo a linha de pensamento de Giddens, a teoria de Bourdieu não escaparia a tendências de reprodutivismo estruturalista posto que o momento neokantiano de reapropriação auto-reflexiva de assunções da experiência dóxica não se traduz em um descrédito imediato dos esquemas e disposições próprios aos interiorizados habitus,

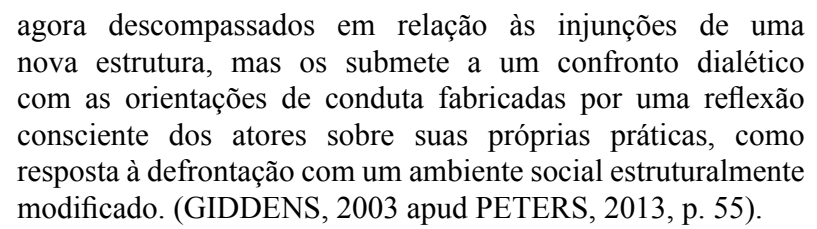

Diante deste panorama crítico, o presente trabalho objetiva assinalar para determinadas deficiências e potencialidades das duas teorias dentro de uma perspectiva contrastiva, valendo-se para isso, nas secções um e dois, de uma sintetização dos seus principais mecanismos operacionais de autopoiesis e anomia para, nas secções três e quatro, confrontá-las com duas questões fundamentais, quais sejam: o momento de recursividade circular dentro da concepção de sociogênese e seus limites metodológicos assim como o dilema da dupla hermenêutica ("ponto cego") no discernimento emancipador do agente (auto)reflexivo.

\section{O conceito autopoiesis na Teoria de Sistemas de Luhmann}

Criticando abertamente a metafísica ontológico-consensual em virtude da sua categórica omissão do não-racional, imperfeito, desviante e caótico, Luhmann dessubstancializa na sua Teoria dos Sistemas (LUHMANN, 1987) as categorias ético-normativas da tradição filosófica ocidental, substituindoas pelo hiperônimo de "diferença" com postulada neutralidade operacional (HARTARD, 2010).

Neste sentido, Luhmann se alinha à tradição de Kant e Husserl e apresenta um mundo que temporaliza e relativiza todas as identidades historicamente institucionalizadas e cuja unidade teleológica não constitui mais o ponto de referência ontológico da teoria. Distanciando-se da visão funcional-estrutural personiana, Luhmann postula a prevalência de princípios de equivalência 
funcional, focalizando a dialética entre sistema e entorno e suas relações de interação (LUHMANN, 1998).

Morfologicamente, o mundo, como orientação epistêmica suprema, carece de entorno e abrange, subsequentemente, todos os sistemas e entornos respectivos, destacando-se os sistemas sociais que proporcionam ao observador a redução da complexidade do mundo dentro de uma lógica fechada e auto-genética que filtra os estímulos exógenos em "atualidades" e "potencialidades" (NEVES; NEVES, 2006). Internamente, os sistemas se bifurcam em suas (sub)ramificações que, respectivamente, se decompõem entre elementos e conexões relacionais.

Operativamente, sua noção de autopoiesis - emprestada da terminologia dos biólogos e filósofos chilenos Humberto Maturanas e Francisco Varela - pressupõe a existência de uma fronteira constitutiva que permite o processamento dialético de distinguir entre "autorreferencialidades" intrínsecas e "heterorreferencialidades" extrínsecas, que ocorre quando o sistema passa a atuar seletivamente. Consoante Neves e Neves (2006), cada operação de um sistema (re)produz essa fronteira encaixando-se em uma rede de futuras operações, na qual, simultaneamente, ele alcança sua própria unidade/identidade. Portanto, a interpretação de fronteira - particularmente concernente os sistemas psíquicos e sociais - não deve ser entendido morfologicamente, mas sim operacionalmente.

Para Luhmann a única operação capaz de sustentar o social de maneira autônoma é a comunicação que, no entanto, reduz o homem ao seu mero portador - a fins metodológicos - na sua função de decifrar os paradoxos na interface com os sistemas sociais. Neste sentido, o sociólogo alemão concebe a comunicação como ponto de partida de uma reflexão social através de uma estrutura de base mais abarcadora na qual se inclui a ação sem, contudo, se esgotar nela (LUHMANN, 1987).

Conforme a linha de raciocínio de Luhmann, o termo "sociedade" é sinônimo de comunicação - entendida como reprodução de seus elementos estruturais e como constante distinção entre interfaces não-ontológicas relevantes ("atualidades") e irrelevantes ("potencialidades") através de processos de descarte e aproveitamento - cuja morfogenética se estrutura pela infinita multiplicação de perspectivas desconstruindo paradoxos da terra incógnita: o entorno (LUHMANN, 1998). Assim, o progresso sintagmático propulsionado pelo momento diferenciador do ser humano correlaciona com o eixo paradigmático, engendrando um complexo conjunto de bifurcações sistêmicas em constante interação (RECKWITZ, 1997).

$\mathrm{O}$ acesso à difusa realidade se vê intermediado por construções internas no processo observacional, embasadas em diferenciações seletivas para dar conta 
da complexidade do entorno, que obedecem restritivamente a mecanismos anticipatórios-controladores de estruturas auto-referenciais endógenas que emulam as próprias "heterorreferências" exógenas via contingência interna.

Conferindo simetria paradoxal à unidade atualizada por processos comunicativos através da diferenciação binária entre o lado operacional positivamente marcado intrassistêmico e o lado negativamente marcado extrassistêmico, as unidades autopoiéticas se complexificam internamente à medida que oferecem relês à combinação de elementos compatíveis situados no entorno, sem, todavia, proporcionar circunstâncias intrassistêmicas estáveis. Dentro do seu paradigma volátil de constante reconfiguração de probabilidades atualizadas e improbabilidades potenciais, a construção de sentido ocorre de forma operacional in actu e perde sua vigência ao se desatualizar.

É oportuno assinalar que, em oposição à concepção da gênese de "campos" de Bourdieu, regida pela lógica de reprodução conflituosa de diferentes disposições de capitais e sua legitimidade, o conceito de Luhmann se opõe, a priori, a qualquer tendência de hierarquização de pessoas e classes conforme diferenças primárias objetivas à medida que incorpora o ser humano dentro de específicas sociedades parciais como portadores e não donos de diferenciadas disposições estratificadoras com o resultado que a própria ordem supersistêmica consiste em uma infinitude de alternativas exploráveis (HARTARD, 2010).

Não obstante, a reprodutividade resta um fato inegável no esboço de Luhmann na sua operacionalidade reafirmadora de diferenças historicamente sedimentadas. Assim, adere, a princípios, à concepção de uma constituição topográfica conforme sua distribuição de capital financeira, de trajetória biográfica profissional entre outros, condicionada, contudo, à existência de uma divisão em sistemas funcionais transcendendo características estratificadoras regidas por elementos inibidores de interdependências que pudessem obstaculizar a lógica de acoplamento de valores positivos ou negativos.

Portanto, a tendência de clusterização nas posições superiores da tessitura hierárquica bourdieusiana se evidencia também na Teoria dos Sistemas de Luhmann, já que o efeito de uma contínua exclusão que se auto-reforça nos níveis inferiores acarreta uma reação de cadeia que interliga todos os sistemas afetados. Consequentemente, a neutralidade operacional de códigos binários se transforma em contato com a realidade social em um instrumento condensador de persistente acumulação de valores positivos ou negativos que engendra a verticalização estratificadora subsumida em padrões de exclusão e inclusão. 


\section{O princípio de anomia dentro da Teoria da Prática de Bourdieu}

Diferenças, em vez de unidades; relações, em vez de substâncias numênicas; operacionalidade em vez de ontologia; progresso infinito em vez de ordem teleológica: a sociologia do conhecimento de Bourdieu, em estreita analogia à Teoria dos Sistemas de Luhmann, descarta momentos aprióricos na descrição da sociedade moderna. Ela substitui, dentro de sua concepção antropológico-filosófica agonística, a visão humanística pautada em ideias normativas últimas pelo princípio de anomia que remete ao conflito existencial travado em arenas de competição por certas categorias de lucros materiais e/ou simbólicos, através do investimento de "capitais" socialmente legitimados de disputa (BOURDIEU, 1979).

Bourdieu enfoca a observação dos mecanismos relacionais dentro da complexa organização do mundo, restituindo o cerne do debate à realidade social - em divergência da postulada abrangência operacional universal de Luhmann.

Consoante Peters (2013), a Teoria da Prática de Bourdieu, como ferramenta heurística de orientação à pesquisa de universos sócio-históricos diversificados, está ancorada na tese da existência de uma inter-relação causal entre as matrizes socialmente adquiridas de produção da conduta individual (habitus), de um lado, e as propriedades estruturais dos contextos de socialização, atuação e experiência dos agentes ("campos"), de outro.

A premissa principal que perpassa a teoria social de Bourdieu e estrutura o continuum topológico da sua concepção da sociedade, reside no potencial generativo da incessante concorrência de recursos que emoldura como mecanismo universal a trajetória historicamente constituída de específicos "campos" emergentes, sendo sua configuração anómica encarnada através da socialização dos atores participando do mesmo horizonte sócio-espacial.

Em analogia ao conceito autopoiético de Luhmann, a paradoxia inicial que postula a existência de uma categoria normativa oculta suas origens e somente pode ser desconstruída pela hipotética fixação numênica $a$ posteriori.

Em vez de nortear-se em horizontes ontológicos na sua funcionalidade, cada "campo" cria - mediante a consolidação gradativa da sua ilusio habitual - suas específicas expectativas e exigências na disposição de diferenciadas formas praxeológicas. Adjudicando ao ser humano o papel de agens dentro da sua constituição histórica, sua unicidade - como lado marcado das diferenciações situadas na topologia social - sucumbe, contudo, ao efeito da "ilusão biográfica", condensada através de uma contingência lógico-formal de 
sequências de vida a base de auxílios conceituais como nome, nacionalidade e gênero, entre outros.

Sua cartográfica ancoragem no complexo relacional da tessitura hierárquica da realidade social se encontra endereçado pelo ser humano através da transposição praxeológica do seu habitus.

Essa abordagem relacional condensa-se no conceito de "campos", visualizados como espaços objetivamente estruturados de relações entre agentes diferencialmente posicionados em função da distribuição assimétrica de recursos materiais e simbólicos, quais sejam, os capitais que funcionam como recursos socialmente eficientes e historicamente consolidados na sua legitimidade.

A distinção binária de Luhmann se transmuta aqui em classificação de pares oposicionais, localizados temporal e espacialmente em um continuum hierárquico que, substanciando a (im)premeditada formação de antagonismos, constituem a sociedade.

Seguindo a linha de argumentação de Hartard (2010), constitui uma das vantagens operacionais da Teoria de Campos de Bourdieu a incorporação de elementos heterodoxos como núcleos analíticos equivalentes, suscetíveis de fornecer as interfaces combinatórias que possam originar os antípodas dos "campos" ortodoxamente constituídos.

Portanto, a morfologia de um "campo" especializado sempre considera ambos os impulsos exógenos - autônomos e heterônomos, em relação à sua compatibilidade interna - em oposição metodológica à teoria de Sistemas de Luhmann cujo modus operandi seletivo apenas incorpora no seu sistema aquelas "heterorreferencialidades" congruentes com sua estrutura intrínseca, inviabilizando a criação de dualidades antagônicas gradativas do continuum hierárquico bourdieusiano. Enquanto as "heterroreferencialidades" disfuncionais coexistem apenas implicitamente como "potencialidades" dentro do código operacional do sistema em Luhmann, cada elemento ortodoxo, segundo a lógica bourdieusiana, pressupõe seu homólogo oposicional localizado na hierarquia social, conferindo, portanto ao antagonismo (social) valor existencial.

Não obstante, Hartard (2010) aponta pela inconsistência epistemológica concernente à imparcialidade numênica, já que o momento anómico figura como "racionalidade" imutável do "campo" e controla a distinção entre elementos ortodoxos ou heterodoxos em relação à lógica vigente.

Portanto, Bourdieu radicaliza, dentro de uma perspectiva neo-kantiana, sua recusa de ambições trans-históricas de diferenciação ou de setorização social 
objetivamente constituída pela divisão de trabalho. Por outro lado, seu conceito metateórico comporta traços materialistas de cunho marxista-weberiano a medida que deflagra a hegemonia dos "campos" específicos da política e da economia, enquanto, paradoxalmente, inclui as auto-descrições dos "campos" arte e ciência como determinações funcionais objetivas dentro do núcleo de análise sociológico destes "campos" (VANDENBERGHE, 1999).

É oportuno assinalar neste momento pela vantagem da neutralidade formaloperacional da teoria de sistemas de Luhmann de um realismo crítico que reduz a distinção entre impulsos funcionais e disfuncionais à uma justaposição funcionalmente equivalente. Rejeitando rigorosamente os fundamentos do racionalismo científico, o sociólogo alemão contorna a "falácia epistêmica" (VANDENBERGHE, 1999) através da introdução do momento paradoxal que, em variação da perspectiva assumida, oferece panoramas alternativos do mundo - sem postular a hegemonia de normatividades trans-históricas.

A admoestada inconsistência metodológica dentro dos fundamentos da Teoria da Prática ressurge com virulência na sua precedência ontológica e metodológica do nível objetivo sobre o nível subjetivo da realidade social (PETERS, 2012; VANDENBERGHE, 1999). Permanece patente na ideia de que, ao que tange o ator leigo, é a desconstrução da "cumplicidade ontológica" entre as disposições dos agentes e seus ambientes estruturais de atuação/ experiência que viabiliza o surgimento de ações fundadas sobre deliberações (auto)reflexivas.

Destarte, a teoria descarta a possibilidade do processo inverso, ou seja, que o próprio momento de auto-aproporiação reflexivo pelo ator origina uma desestabilização total ou parcial daquela cumplicidade.

\begin{abstract}
O ajuste dar-se-ia por meio da operação tácita ou "pré-reflexiva" de um habitus socialmente estruturado (inculcado a partir de uma trajetória experiencial percorrida ao longo de uma ou mais posições em uma estrutura objetiva de relações) e estruturante (pois tende a reproduzir as estruturas que o constituíram quando mobilizado recursivamente nas ações dos indivíduos). (PETERS, 2013, p. 52, grifo do autor).
\end{abstract}

Diante desta problemática, os detratores da Teoria da Prática coincidem em sinalizar para uma forte lógica de reprodutivismo, visto que o sujeito tende a reincidir nas mesmas estruturas sociais objetivas (PETERS, 2013).

Face à denunciada inflexão neo-objetivista, Bourdieu retorque assinalando pelo momento potencialmente emancipatório, proporcionado por processos reflexivos de "anamnese" sobre as significações inconscientemente interiorizadas, 
que se aparenta aos esforços da autorreapropriação neokantiana, porém comumente reservado à capacidade esclarecedora da própria ciência social.

\section{A recursividade operacional dos conceitos autopoiesis e anomia}

Consoante as asserções de Hartard (2010), os princípios fundamentais da gênese construtivista inerentes a ambos as teorias sociais se originam no funcionamento operacional de circuitos autárquicos a medida que os outputs da estruturas sociais, dentro da alegorizada máquina geradora de processos históricos, re-alimentam os novos inputs. Estes processamentos funcionais sedimentam, proporcionalmente à dimensão temporal, sua própria trajetória em contingências históricas (legítimas) sem, no entanto, vislumbrar o momento inicial da sua dinâmica recursiva.

A ordem assim constituída se sustenta na sua auto-referencialidade estável, sem, contudo acusar movimentos estáticos. Não obstante, define suas próprias regras operacionais que restringem o acesso de impulsos transformadores exógenos.

Seguindo à linha de argumentação de Hartard (2010), as estruturas teóricas do conceito de Luhmann se orientam em uma lógica evolucionária não-linear sem possibilitar retraçar seu momento original, a não ser através da introdução hipotética a posteriori de "mitos" numênicos dentro da sua circularidade. Metodologicamente, toda operação inicial remete para um paradoxo já que a distinção entre "atualidades" e "potencialidades" requer uma diferença inicial dentro do núcleo da autonomia autopoiética das estruturas que controla e viabiliza a construção de morfologias mais complexas ao usurpar as "potencialidades" aleatórias do seu entorno.

Neste sentido, Hartard (2010) aponta para a vigência de uma lógica similar no âmago do conceito anti-ontológico de Bourdieu com respeito ao seu postulado da transformação de sequências operacionais aleatórias em sistemas contingentes, a condição que os elementos praxeológicos resistem a uma prova de consistência a posteriori, conferindo sentido ex post à sua genética operacional que, segundo princípios de recursividade, se complexifica nas suas estruturas ao construir suas próprias origens.

A suposta coerência nas lógicas emergentes discerníveis para o observador objetivante se evidencia, portanto, como uma ilusão, posto que as incessantes reconfigurações dos seus fenômenos virtualmente engendrados obedecem a uma fixação operacional arbitrária inicial cuja origem genética se obscurece. Paradoxalmente, a crescente dependência histórica de estruturas sociais se acompanha por uma dessubstancialização da sua suposta ordem social, 
ofuscando seu momento de anomia que converte as assimetrias sociais em diferenças simbólicas inalteráveis e, subsequentemente, imuniza o status quo contra destrutivas indagações sobre suas origens que pudessem comprometer sua legitimação (PETERS, 2013).

Em tese, cada operação pode ser concebida como elemento independente das estruturas superordinadas. No entanto, sua margem de atuação se restringe dentro da sua própria circularidade intrassistêmica, em virtude do recurso antecipatório ou retrospectivo ao passado ou futuro, condicionando seu potencial de desenvolvimento endógeno às pré-configurações vigentes na lógica processual da estrutura autônoma. Portanto, a aleatória dinâmica de ocorrências emergindo no eixo diacrônico alimenta a temporalmente irreversível genética evolutiva das estruturas/sistemas, reajustando permanentemente a sua composição interna nas suas dimensões presente, passado e futuro.

No caso de Luhmann, prevalecem mecanismos de triplo processamento circular-consolidador dentro do entrelaçamento recursivo entre operação circular e estrutura, quais sejam: variação, seleção e reestabilização; sendo que a variação - como "potencialidade" procedente do entorno assimetricamente organizado - em um primeiro momento pode ser positivamente reconhecida como correlato compatível à semântica processual intrassistêmica.

Posteriormente, pode ser atualizada e incorporada às estruturas se for homologada sua capacidade operacional em ulteriores seleções - originando modificações internas que re-estabilizam a estrutura e reduzem a probabilidade de dissolução sem, contudo, descartá-la sui generis.

Assim, a auto-referencialidade recursiva dos sistemas, operando transformações seletivas na sua fronteira sem poder transcender os limites estruturados e estruturantes de sua incumbência, introduz a problemática de uma metamorfose ad infinitum, cujo "ponto cego" assinala para a incognoscibilidade do sujeito de conceber a si mesmo e ao entorno incomensurável dada a atomização das referências norteadoras e dotadas de sentido.

Consoante Neves e Neves (2006), a circularidade epistemológica reside no fato de o conhecimento científico se encontrar amputado na sua função de acessar o entorno,

ou seja, a verdade não fornece nenhuma garantia de contato com um "mundo real" - é auto-referente e, mesmo operando por heterroreferências, por exemplo, quando o sistema se refere a fenômenos do entorno ainda assim utiliza suas próprias comunicações para fazê-lo, distanciando-se de um modelo de sociedade holístico. (NEVES; NEVES, 2006, p. 21). 
Luhmann, neste caso, adere à teoria cognitiva realista, cujas referências se embasam em teoremas cientificamente edificados, em detrimento de aproximações individuais ao problema. Consequentemente, a realidade percebida côngrua com a construção da nossa própria perspectiva, que se manifesta em um recursivo retorno de um passado do sistema científico comunicativamente cristalizado.

Estas agregações de sentidos engendrados in actu viabilizam certa dinâmica internamente regulamentada de auto-encerramento e autorreferêncialidade que, sem petrificar-se em uma estática basal, reduz a aleatoriedade de futuras ocorrências singulares ao construir sua própria circularidade que recorre a um passado ainda visível e antecipa um futuro já discernível, levando todas as "potencialidades" não marcadas dentro do seu acervo genético.

O impacto estruturante desta engrenagem autopoiético pressupõe a existência de uma memória passível de discernir entre operações de descarte de construções formais fracassadas e recorrer a construções formais exitosas, sem, no entanto, visualizar seu próprio "ponto cego", ou seja, conceber suas alternativas existenciais. Portanto, remete para um conceito histórico de realidade legitimadora da sua inquestionável e inalcançável autoridade como resultado de seleções sucessivas a partir do universo infinitivamente complexo de atualidades e potencialidades.

$\mathrm{O}$ efeito de permeabilidade restritiva de proporcionar interfaces historicamente constituídas com função de relê para agregações complementares reduz a complexidade do seu entorno, providenciando um alto grau de variação combinatória à possível incorporação de elementos exógenos que consolida sua redundância intrassistêmica.

Tecnicamente, a elasticidade da recursividade intrassistêmica descarta determinismos ou, pior, a (auto)destrutiva redução da aleatoriedade no processamento seletivo entre estruturas e opções "heterorreferenciais".

Não obstante, prevalece o princípio autopoiético de amortizar eventuais intrusões ao proporcionar interfaces combinatórias emergenciais para garantir a integridade sistêmica. Evidencia-se, neste ponto, a ambiguidade da teoria de Luhmann entre o auto-encerramento, que restringe o potencial de difusão ao reduzir a capilaridade operacional nas suas fronteiras, e sua permeabilidade "arriscada", capaz de sobrecarregar os mecanismos de incorporação ativa/ passiva.

Neste contexto, Hartard (2010) salienta que, pese às premissas estruturantes de autopoiésis, auto-determinação e auto-organização do seu construtivismo radical, não prevalece uma ordem de autarquia funcional do sistema já que este não pode prescindir de "interferências" extrínsecas, porém obedece nos seus 
processos de integração e complexificação interna às regras intrinsecamente geradas.

Assim, o sistema se alimenta de "heterorreferencialidades" do seu entorno através do recurso aos inerentes critérios de aproveitamento ou recusa, constituindo assim uma fronteira operacional com a terra incógnita na sua órbita que cria sua própria temporalidade através de filtros de diferenciação interna que possibilitam a transposição assimétrica dos impulsos exógenos às estruturas auto-referenciais intrínsecas.

Em função da incognoscibilidade do impacto para ambas as dimensões temporais presente e passado, provocado por contextos de sentido emergindo em operações localizadas no futuro, o conceito praxeológico de Bourdieu considera o momento de sua atualização como horizonte temporal aberto e incorporado em estruturas semânticas, sem, contudo, obedecer a procedimentos teleológicos. A observação in actu obscurece o questionamento refletivo sobre as relações e mecanismos operacionais institucionalizadas, considerados como necessidades ontológicas, já que a aparente autonomia existencial das estruturas discerníveis no momento não deixa vislumbrar seus princípios axiológicos.

Em consoância com a proposta de Luhmann (1987), as estruturas disponíveis que alegorizam de forma sustentável a topologia hierárquica das relações sociais assimetricamente organizadas acusam um alto grau de estabilidade interna proporcional ao tempo percorrido. Estas são objetivamente internalizadas pelo sujeito que figura como interface de acoplamento entre estruturas incorporadas como habitus e "excorporadas" como práxis.

Agindo como estruturas estruturadas construídas para atuar como estruturas estruturantes, a concepção circular de habitus condensa as experiências topologicamente e temporalmente situadas na mátrix social, observáveis como diferentes formas de práxis. Estas engendram, respectivamente, diferenças operacionais constituintes de sentido em íntima analogia ao princípio chomskyano da gramática generativa.

Para escapar às tendências estruturalista-deterministas, Bourdieu recorre ao mesmo princípio que Luhmann, qual seja: enfatizar a emergência de estruturas dinâmicas dentro do conceito de habitus, visualizado como sistema de disposições aberto à confrontação com novos impulsos exógenos, cuja ausência - a título de invariações constantes - significaria a paralisia sistêmica. Seguindo as digressões do sociólogo francês, o aleatoriamente produzido choque entre ocorrências singulares e uma controladora lógica estrutural aponta pelo imanente potencial de criatividade do ator em recorrer a procedimentos conhecidos ou em adaptar uma nova operacionalidade proporcionada pela circunstância ocorrida. 
Assim, o poder generativo do sujeito dentro da margem de suas restrições historicamente constituídas sinaliza pela pressuposição central de um corpo socializado, em distanciamento das premissas da teoria fenomenológica que parte de um sujeito transcendental inteiramente livre.

Destarte, a elasticidade do espaço social acusa uma causalidade recursiva entre posições sociais e disposições do habitus que se alimentam dentro de um acervo de possibilidades a serem ativadas conforme as circunstâncias limitadoras, enquanto cada posição de "campos" dispõe de potenciais de uso a serem atualizados e aproveitados de forma diferenciada em variação do habitus respectivo.

Em congruência com as restrições evidenciadas no caso da teoria de Luhmann, a identificação de um momento original dentro da operacionalidade circular em Bourdieu termina em um busca do regressus ad infinitum. Os elementos introduzidos na sua trajetória generativa sempre remetem para fundamentos anteriores, como procedência, posse, educação, entre outros, alimentando a engrenagem da incessante reprodução de desigualdades sociais que se assemelham a um jogo aonde cada participante depende de todos os resultados tanto positivos como negativos daqueles que the precederam (HARTARD, 2010).

$\mathrm{O}$ entrelaçamento das dimensões de um passado relembrado e um futuro incerto se produz através da atualização e desatualização do centro de interesse do habitus que associa os horizontes prospectivos com certas probabilidades canalizadoras originadas no passado através de processos sedimentários que constroem o agregado consistente para a sua retrospectiva observação, inacessível para indagações sobre as suas alternativas praxeológicas.

Assim, a história produz na sua lógica recursiva um universo de um infinito número de combinações, encerradas em um sistema finito de restrições em forma de potencialidades. Figurando como espaço de possibilidades objetivas de posições disponíveis e opções praxeológicos vacantes, sua morfologia se constitui de lacunas estruturais portadoras de potencialidades virtuais, a serem ativadas somente por aqueles portadores de habitus que as reconheçam como acessíveis para suas próprias disposições.

Em consoância com o esboço da sociogênese de Luhmann, a consolidação das estruturas para Bourdieu, portanto, acusa tendências de auto-encerramento da sua semântica interna na criação de probabilidades reativas a possíveis elementos "heterorreferenciais", sem, no entanto, poder prescindir deles. 


\section{O dilema da dupla hermenêutica no "ponto cego" do momento emancipador}

Conforme Hartard (2010), o motivo do "ponto cego" perpassa como constante todas as obras teóricas de Luhmann e Bourdieu: Estruturas têm origens - que permanecem terra incógnita; elas se desenvolvem em dependência da sua história - inacessível para ela; elas atrelam sua operacionalidade a semânticas historicamente constituídas - sem admitir princípios teleológicos; elas percebem o mundo como universo assimétrico esvaziado de sentidos - extraindo sempre seu próprio sentido existencial. É patente destacar que nenhum dos dois conceitos teóricos - anomia e autopoiesis - se auto-questiona sobre sua própria consistência numênica, apesar da evidenciada existência de observadores "externos" que já atestaram a vigência de princípios norteadores que condicionam a sua própria operacionalidade.

Assim, a lógica da emergência de espaços sociais especiais em Bourdieu, e sistemas sociais em Luhmann respectivamente, sinaliza pela tensão entre visibilidade e invisibilidade do seu código operacional, dando acesso a diferentes visões cosmológicas, sem, contudo, permitir o acesso na sua integralidade. Paradoxalmente, o diferenciado acesso à realidade a partir da infinitude de perspectivas alternativas engendra as próprias diferenças multidimensionalmente multiplicadas da sociedade.

Focalizando a teoria de Luhmann, o discernimento entre visível e invisível se efetua mediante a contrastação induzida pelo ato observacional que distingue entre um lado marcado atualizado, compatível com ulteriores combinações operacionais, e outro lado não-marcado, potencializado, sem, no entanto, conceber a dialética inerente à assimetria dos pares opostos.

Ergo, cada momento de taxonomia binária implica seu próprio "ponto cego" conforme a necessidade imperativa inserida na semântica do sistema, a "latência estrutural-funcional", (strukturfunktionale Latenz) conforme a terminologia de Hartard (2010, p. 38).

O mesmo princípio domina o processamento circular do conceito de habitus em Bourdieu, a medida que todas operações no espaço social engendram exatamente aqueles esquemas de diferenciação que logo servem de base para momentos de observação e cognição. Conferindo assim sentido para os atores, estes vêm sua percepção superdeterminada por ele sem poder possuí-lo. Em congruência com os limites assinalados para a teoria de Luhmann, o nível de reflexão alcançado através de um posicionamento observador distante e distinto torna visível a "verdade" do outro observador - ao preço de escamotear seus próprios horizontes de sentido. 
Sintetizando, o dilema subjacente ao entrecruzamento dereposicionamentos esclarecedores e cegueiras intrínsecas à taxonomia objetivante sinaliza pelos limites de capacidades de autoapropriação emancipadora do sujeito, ressalvando que, a pesar das citadas ausências ontológicas, existem possibilidades diferenciadas à objetivação objetivante (HARTARD, 2010; VANDENBERGHE, 1999).

No caso de Luhmann, o primeiro nível de observação (a) restringe sua percepção a uma realidade imediata inquestionada proporcionada pela taxonomia binária sim/não que, na sua inalterada transposição ao seu inconsciente, postula a absoluta veracidade coercitiva do mundo sem inconsistências e alternativas potenciais. Entretanto, as observações sobre as observações remetem para o observador de segunda ordem (b) que assinale objetivamente pelas suas latentes potencialidades, trilhas não-marcadas e estruturas semânticas irrefletidamente interiorizadas, sem, todavia, poder garantir a irrefutável legitimidade da sua construção, dada a prevalência de um momento subjetivo inerente à própria perspectiva. Este distanciamento revela então as inter-causalidades e referências lógicas dos sistemas funcionais entrelaçados, que serão objeto de discernimento da observação da terceira ordem (c), capaz de deflagrá-las como espelho subjetivo da morfologia do próprio sistema que nunca alcança seu ponto arquimédico.

Portanto, a formulação de alternativas de conceitos da realidade nunca abstrairá de categorias subjetivas da distinção no terceiro nível sendo que a objetividade objetivante externa nunca se concretiza em virtude do próprio "ponto cego" do seu observador inserido. Subsequentemente, o acesso à totalidade da verdade objetiva permanece uma mera ilusão auto-referencial.

Emíntima analogia, Bourdieu pressupõe na sua sociologia de conhecimento uma escala tridimensional de discernimento crítico, incumbindo ao primeiro nível (a) a percepção common sense da realidade imanente como "experiência dóxica" que se encontra condensada no consenso axiomático entre o sentido praxeológico e a objetividade inerente ao conceito do mundo (ilusio), havendo uma congruência inquestionada sobre o habitus encarnado e as estruturas sociais "excorporadas" ("cumplicidade ontológica").

O reconhecimento tácito sobre o fato que a observação primária do mundo social não coincide com o espelhamento mecânico do espaço social consolida, consoante Hartard (2010), a legitimação do poder simbólico que transmite a ilusão da irrefutabilidade das institucionalizadas configurações dominantes no âmago dos dispositivos de discernimento, cuja revelação desilusionante incumbe ao observador da segunda ordem (b). Este deflagra que a organização de posicionamentos na realidade social irrefletida não pode congruir com a 
hierarquicamente diferenciada ancoragem do indivíduo dentro do continuum social, em virtude da circularidade restritiva da trajetória biográfica dos atores que engendra - através do diferenciado grau de formação escolar e socialização no mundo, entre outros fatores - desigualdades que se repercutem nos respectivos habitus de classe com potencial de reforçar as assimetrias identificadas, correlacionando os posicionamentos a uma diferenciação vertical entre classes e a uma distinção horizontal entre os "campos" que se entrecruzam difusamente.

A adequação da perspectiva com o respectivo "campo" permite a visualização estruturalista de suas semânticas e lógicas intrínsecas. Não obstante, em decorrência da falta de objetivação da práxis em relação ao seu "campo", o observador de segunda ordem não exclui seu "ponto cego" associado ao pertencimento a um "campo" determinado com uma semântica específica, que se encontra temporalmente abstraído e epistemologicamente condensado sob a visão "escolástica" da terceira ordem (ci). Esta, na tentativa de reconstruir a "lógica da lógica" (HARTARD, 2010, p. 32), sucumbe inevitavelmente à tendência de ofuscar do seu modelo atemporalizado a ilusio da realidade percebida ao primeiro nível.

Apenas através da "dupla ruptura" que admite a inclusão da subjetividade dentro do objetivo - a objetivação da objetivação (cii) - o sujeito distanciado concebe a identidade entre práxis subjetiva e estrutura objetiva na dupla realidade, ora na ingênua concepção da realidade fundamentada em uma práxis "autêntica", mas condizente com a cegueira do posicionamento que encarna tacitamente as estruturas de dominação simbólica, ora nos modelos explicativos cujo ponto cego reside na ilusão da identidade entre realidade e abstração.

Sintetizando, ambas as teorias convergem em assinalar para um triplamente diferenciado acesso à realidade subjetiva do mundo, quais sejam: (a) a internalização imediata não-reflexiva - "doxa passiva" - que concebe todos seus elementos como necessidades inquestionáveis; (b) o reconhecimento coerente aos regulamentos em vigência dentro do sistema ou do campo respectivo, capaz de distinguir ilusórias necessidades de contingências e assinalar para alternativas latentes; (c) o discernimento reflexivo-teorizante capaz de deixar plausível a seleção de uma só concepção do mundo entre outros sem poder pleitear, contudo, a irrefutabilidade da sua suposição. Isso revela a quintessência lógica da incapacidade de visualizar ou acessar à integralidade do mundo em suas contingências e necessidades já que todas as três perspectivas implicam necessariamente a cegueira do "ponto morto" na sua cognoscibilidade. 
Seguindo a linha de pensamento de Luhmann, a superposição de díspares diferenciações multidimensionais entre sistema/entorno, cria um mundo poliperspectivo que admite diferentes representações da realidade subjetiva, sem, no entanto, orientar-se em um posicionamento superior capaz de abarcar as únicas verdades e razões teleológicas. Assim, a incessante especialização de (sub)sistemas se arroga dentro de sua semântica operacional interna o privilégio de reclamar a totalidade da sua cognoscibilidade da realidade "verdadeira" que confere seus próprios horizontes de sentido, inviabilizando a convergência dentro de um conceito do mundo com abrangência universal.

Congruendo com a visão atomizada de Luhmann, Bourdieu proclama a dissolução de unidades ontológicas do mundo, uma vez que a observação abstrai do universo visível e remete para os mundos especiais e microcosmos originados pela diferenciação de "campos" que operam uma ruptura com o common sense e o pertencimento dóxico na realidade cotidiana, reintegrando retroativamente os conceitos científicos ao senso comum ("dupla hermenêutica").

\section{Considerações finais}

Constituiu objetivo deste trabalho elucidar sobre as principais divergências e convergências epistemológico-metodológicas da Teoria dos Sistemas (Luhmann) e da Teoria da Prática (Bourdieu), valendo-se para isso um contrastivo insight em seus fundamentais momentos operacionais.

Ressaltou-se que a recursividade inerente ao conceito construtivistagenerativista de práxis e sistemas em Bourdieu e Luhmann - em vez de ser antecipadamente rotulada como mecanicista círculo vicioso - pressupõe existencialmente a incorporação de elementos exógenos com capacidade transformatória das estruturas historicamente sedimentadas (Luhmann), respectivamente, dos corpos socializados (Bourdieu), através de processos de incessante distinção e diferenciação, que ocorrem, contudo, dentro de estabelecidas restrições.

Assim, a intercausalidade evidenciada em inúmeros estudos empíricos, entre a ação individual subjetivamente produzida e as tessituras estruturais, institucionais e culturais das formações societárias em que os sujeitos se encontram ancorados, acusa no caso do sociólogo francês uma evidente inflexão marxista-weberiana a medida que enfatiza a hegemonia numênica dos campos da economia e política no processo evolutivo da sociogênese (PETERS, 2013; VANDENBERGHE, 1999).

O horizonte de expectativas aponta, assim, claramente para seus limites em termos probabilísticos, sendo que a paralelização de dois fios 
reciprocamente condicionados de história - a forma exterior da estrutura e a forma individual do ator - cria em largas medidas homologias entre as exigências à realidade e a realidade da práxis. Em caso de incongruências provocadas por impulsos exógenos, pode-se originar uma alteração radical das suas disposições (hysteresis) ou ocorrer o contrário: podem manter-se inalteradas em decorrência da insuficiente elasticidade do habitus em reagir às reconfigurações.

A despeito da focalização formal-operacional da sua proposta construtivista radical, indagando sobre a dialética relação comunicacional entre sistema e entorno a partir de uma interpretação neo-kantiana que relativiza e temporaliza as identidades e estruturas historicamente constituídas, Luhmann advoga, em evidente analogia ao conceito bourdieusiano, por uma concepção diferencialfuncional do mundo.

Neste caso o processamento evolutivo se realiza através da seletiva integração descomplexificadora de "heterorreferencialidades" procedentes do entorno difuso dentro da semântica de sistemas autopoiéticos operacionalmente fechados. Assim, a gradativa sedimentação da sua morfologia autônoma proporcional à dimensão temporal reduz, no seu momento recursivo-circular entre passado e presente a potencialidade transformadora de elementos extrínsecos, acusando tendências de irreversíveis clusterizações de estruturas hegemônicas.

Paradoxalmente contrariando a refutação de instâncias normativas consensuais, ambos os autores, portanto, convergem em enfatizar o princípio "ontológico" da manutenção e defesa da autonomia dos "campos" e sistemas historicamente constituídos contra eventuais intrusões heterodoxos, entendendo autonomia como categoria absoluta de uma semântica operacional com forças quase imanentes - autopoiesis - (Luhmann) ou como categoria metodológico relacional - "campos" - (Bourdieu) que questiona a sua própria gênese como produto histórico.

Admitindo o caráter descritivista-construtivista das suas digressões teórico-metodológicas que justificou o surgimento de posicionamentos críticos que reclamam da ostentada neutralidade observacional dos sociólogos diante dos determinismos sociais historicamente transmissíveis, Luhmann e Bourdieu se esforçam em assinalar pela função esclarecedora-desilusionária da sociologia de conhecimento em sua "missão" legitimizada de apontar para alternativas dentro da ordem social vigente que se rodeia de uma falsa aura de necessidade. Postulando uma dinâmica diferencial existencial desprovida da sua fixação teleológica que, não obstante, recorre a uma estática basal de estruturas hegemônicas, na concepção de Luhmann e Bourdieu, o melhor dos 
melhores dos mundos nunca pode ser perfeito e, portanto, é o melhor dos mundos em que vivemos.

Dentro da perspectiva agnóstica (Luhmann), respectivamente agonística (Bourdieu) do mundo, ambos pleiteiam pelo emancipador questionamento crítico-deflagrador do status quo interiorizado pelo sujeito, suscetível de restituir a capacidade de discernir as aparentes necessidades dóxicas da dupla contingência (Luhmann), respectivamente da legitimação hierárquica disfarçada (Bourdieu) ao observador da terceira ordem. Este pode, dentro da sua auto-reflexão esclarecedora, enveredar por possíveis trilhas alternativas dentro da (sua) trajetória biográfica sem, todavia, identificar com objetividade última o único e verdadeiro caminho. Enquanto Luhmann desconstrói metodologicamente qualquer ponto arquimédico capaz de conferir coerência à assimetria existencial do mundo - desmascarando até os conceitos ontológicos de racionalidade, razão, moral como produto histórico de uma específica operacionalidade sistêmica na sua pretensão de se arrogar a legitimação universal, Bourdieu não cansa de resgatar resquícios de verdades normativas dentro da realidade (pós-) moderna ao recorrer à "introspecção" auto-refletiva.

Conforme Hartard (2010), os limites auto-lógicos da auto-observação, reconhecidos por Luhmann são ofuscados dentro da ilusio do ceticismo radical em Bourdieu, que advoga por um utopismo racional como categoria intermediária entre voluntarismo e fatalismo que deve incitar o observador reflexivo a se engajar em aqueles "campos" de conflitos que permitam efetuar transformações das hegemonias simbólicas contingentes.

Em oposição epistemológica à distinção binária entre operações funcionais e disfuncionais de Luhmann, a propalada análise auto-reflexiva em Bourdieu se evidencia como cópia da semântica dominante legítima que se opõe com toda sua autonomia sedimentada contra qualquer tentativa "subversiva".

É oportuno sinalizar pela significante consistência metodológica da Systemtheorie que, em divergência à deflagrada superioridade trans-histórica de racionalidades últimas de legitimação atribuída aos "campos" da economia e política do conceito bourdieusiano, cuja desestabilização emancipadoraimaginária incumbe ao "imperativo categórico" alegorizado de forma imaginária na virtude da razão em forma de uma práxis social regulativa, Luhmann remete para a contingência formal de forças contrárias, involucradas em conflitos de legitimidade intersistêmicos e desabilitadas de operar fora da sua própria autonomia. Portanto, descarta a existência de uma instância normativa-regulativa suprassistêmica.

Apesar das supracitadas vozes dissidentes que convergem em identificar significantes vestígios neo-objetivistas nos fundamentos metodológicos de 
Luhmann e Bourdieu, cabe ressaltar o mérito atribuído as suas digressões sociológico-filosóficas na sua tentativa de traduzir a constatada assimetria e "dinâmica" dissonância imperante no mundo (social) em uma Weltanschauung descritiva alicerçada na dialética diferenciação que solda irrevogavelmente agência e estrutura.

Assim, o esgarçamento de tessituras normativas e verdades teleológicas inviabiliza qualquer tendência unificadora - a não ser de sistemas e estruturas hegemônicas cuja legitimação historicamente constituída perpassa, ora de forma oculta, ora de forma ostentativa, a morfologia (social) do universo conforme Luhmann e Bourdieu.

Incumbe à sociologia de conhecimento a tarefa de infundir objetividade objetivante no sujeito fixado na camisa de força recursiva-circular entre seu passado, presente e futuro, que paradoxalmente já delimita o momento emancipador ao assinalar para seu "ponto cego" cuja existência pode ser reconhecida, porém nunca superada.

\section{Referências}

BÜHL, W. L. Luhmanns Flucht in die Paradoxie. In: MERZ-BENZ, P.-U.; WAGNER, G. (Orgs.). Zur Kritik der systemtheoretischen Systemtheorie von Niklas Luhmann. Konstanz: Universitätsverlag, 2000, p. 225-256.

BOURDIEU, P. Entwurf einer Theorie der Praxis: auf der ethnologischen Grundlage der kabylischen Gesellschaft. Frankfurt a.M.: Suhrkamp, 1979, 493 p.

HARTARD, C. Differenz der Differenz. Luhmann und Bourdieu: Zwei Soziologen des Unterschieds. In: HARTARD, C. (Org.). Kunstautonomien. Luhmann und Bourdieu. München: Verlag Silke Schreiber, 2010, p. 1-69.

LUHMANN, N. Soziale Systeme. Grundriß einer allgemeinen Theorie. Frankfurt a.M.: Suhrkamp, 1987, 675 p.

Die Gesellschaft der Gesellschaft. Frankfurt a.M.: Suhrkamp, 1998, 1164 p.

NEVES, C. E. B.; NEVES, F. M. O que há de complexo no mundo complexo? Niklas Luhmann e a Teoria dos Sistemas Sociais. Sociologia, Porto Alegre, v. 8, n. 15, jan/jun. 2006, p. 182-207.

PETERS, G. O social entre o céu e o inferno. A antropologia filosófica de Pierre Bourdieu. Tempo Social Revista de Sociologia da USP, São Paulo, v. 24, n. 1, 2012, p. 229-261.

PETERS, G. Habitus, reflexividade e neo-objetivisimo na teoria da prática de Pierre Bourdieu. Revista Brasileira de Ciências Sociais, São Paulo, v. 28, n. 83, out. 2013, p. 47-71. 
RECKWITZ, A. Kulturtheorie, Systemtheorie und das sozialtheoretische Muster der InnenAußen-Differenz. Zeitschrift für Soziologie, Bielefeld, v. 26, n. 5, 1997, p. 317-336.

VANDENBERGHE, F. "O real é relacional": uma análise epistemológica do estruturalismo gerativo de Pierre Bourdieu. Tradução de Gabriel Peters. Sociological Theory, v. 17, n. 1, 1999 , p. 32-67.

Submissão em: 29/01/2016

Aceite em: 29/11/2016

Stephan Treuke é doutorando no Programa de Pós-Graduação em Ciências Sociais: Universidade Federal da Bahia. Mestre em Geografia Humana e em Filologia Românica: Justus-Liebig Universität, Alemanha. Programa de pós-graduação em Ciências Sociais.

Endereço: Programa de pós-graduação em Ciências Sociais. Estrada de São Lázaro, 197, Salvador/Bahia, Brasil. CEP 40210-730 E-mail: StephanTreuke@hotmail.de 